\title{
Fear Avoidance as the Body's Defence Mechanism for Death
}

\author{
Jérôme Alric ${ }^{1,2}$, Bénézech Jean-Pierre ${ }^{1}$ \\ ${ }^{1}$ Department of Palliative Care, University Center Hospital, Montpellier, France \\ ${ }^{2}$ The Research Laboratory Interdisciplinary Center, University of Paris Est, Marne-la-Vallée, France
}

Email address:

j-alric@ chu-montpellier.fr (A. Jérome),.jp-benezech $a$ chu-montpellier.fr (B. Jean-Pierre)

\section{To cite this article:}

Alric Jérome, Bénézech Jean-Pierre. Fear Avoidance as the Body's Defence Mechanism for Death. American Journal of Psychiatry and Neuroscience. Vol. 6, No. 3, 2018, pp. 61-66. doi: 10.11648/j.ajpn.20180603.12

Received: June 19, 2018; Accepted: July 24, 2018; Published: August 28, 2018

\begin{abstract}
Today within the sphere of chronic pain, the mechanism of fear avoidance is a well-known concept that has been substantiated through international literature in the field. As patients believe that work and physical activity will aggravate their pain, the logical response is to progressively implement avoidance strategies for particular physical movements. This will thus tend to perpetuate a feedback loop: pain - non-confrontation - weakening - pain. In this article, we aim to show that this concept is transferable to the field of serious illness and palliative care, even if the term is used differently on a therapeutic level. The idea of avoidance here relates to death and can be defined in the following way: fear of death/distress - nonconfrontation regarding death - life/death instinct ambivalence. Because of this psychological life-saving mechanism, the subject who is ill remains in the stage of life/death instinct ambivalence, in other words, living. The implications of this model for clinical practice are completely new, whether applied at the moment of diagnosis, during the psychological experience that accompanies the illness or even in the aforementioned final phase of life. the mechanism of fear avoidance represents a real life-saving defence, whether from the moment of diagnosis of serious illness, during the psychological process that accompanies the illness, or in the final moment of death, allows the patient to die, psychologically speaking, more comfortably.
\end{abstract}

Keywords: Diagnosis, Delirium, Fear Avoidance, Defence Mechanism, Palliative Care

\section{Introduction}

The concept of fear avoidance [1], which comes from the arena of chronic pain can be summarised in the following way: as patients believe that work and physical activity will aggravate their pain, the logical response is to progressively implement avoidance strategies for particular physical movements. This will thus tend to perpetuate a feedback loop: pain - non-confrontation - weakening - pain [2]...

In this article, it will be shown that this concept is transferable to the field of serious illness and end of life. These concepts connect directly to the work of contemporary French studies in psychoanalysis concerning psychological defence mechanisms when faced with death [3-5] and should be used differently on a therapeutic level.

The idea of avoidance here relates to death and can be defined in the following way: fear of death/distress - nonconfrontation regarding death - life/death instinct ambivalence.

In fact, no matter at what moment the patient is diagnosed, during the psychological experience of the illness or even during the last phase of life, those who succeed in having an ambivalent attitude toward death, due to the life-saving mechanism of avoidance, live better than those patients who remain bewildered when faced with this eventuality. Here the process of fear avoidance rarely produces a substantial, direct, and continuous avoidance, but instead causes a psychological ambivalence which aids the patient in his preparation for death. At the same time, the patient may become recklessness, or irrational as if reality had suddenly evaporated. This "simultaneous progression of two contradictory lines of thinking" [6], is not problematic, but rather can be thought of as useful for the inner life of the subject. 
What it will be shown in the arena of serious illness and the end of life, contrary to the field of pain, is that fear avoidance is the mechanism that allows the subject to remain alive with the illness [7].

\section{Method}

Clinical experience, confrontation to psychoanalytic and philosophical litterature, linkage between scientific research and and our observation, guided this research work. It provides the reader new means of interpreting clinical facts which challenge a lot of clinicians.

\subsection{Fear Avoidance}

The concept of fear avoidance both highlights and explains the cognitive-behavioural position that impedes the subject from acting in the presence of pain. This position comes from the patient himself; in fact the patient is not conscious of the feedback loop, pain - non-confrontation - weakening - pain, that is at work within him and which shuts down all possibilities of life. Faced with this counterproductive impasse, treatment options offer the patient the option of substituting confrontation with activity, with the reassurance that the patient can enter slowly into a new virtuous circle [8].

Psychologically speaking, it is profound fear that produces avoidance to the situation in the body's defence; the perpetuation of this avoidance inhibits the patient from returning to normal life. The patient, often holding catastrophic beliefs (particularly in relation to chronic pain) is convinced that it is the activity that is causing him pain [9]. He is not able to see the aspect of defence that can be worked with through the correct treatment program. In truth, this fear of pain, that stems from beliefs about the harms of physical activity, can be worked with as a false belief. Through techniques of reclaiming the activity, numerous authors have shown that it is possible to implement a treatment plan of confrontation alongside the fear of pain [10-11]. Consequently, it is in the deconstruction of the patient's belief that will be beneficial. With regards to serious and life-threatening illness, the avoidance refers to death itself. Here we have defined it as fear of death/distress - non-confrontation regarding death life/death instinct ambivalence. This feedback loop (at least the beginning) is reminiscent of the pain cycle. We will see here that that this loop is a natural and spontaneous psychological reflex, a reflex that is in place when something touches the core of the ego, and more specifically regarding the fantasy of eternity [12].

Regarding proposals for treatment, just as in the case of working within the context of chronic pain, it would be possible to tackle the issue from a different angle, where there are suitable techniques to deal with and change the patient's beliefs concerning death. It is precisely the biproduct that could lead to a pragmatic and utilitarian use of E. Kübler-Ross' [13] model with the idea of mentalising death, to subdue it. In this taming, the patient would be able to leave this world more peacefully. This belief is effective in a world that presupposes life after death, but it falls apart in our modern Western world.

\subsection{When the Concept of Fear Avoidance Meets Freud's Denial of Death}

This attitude of avoidance toward pain calls to mind what Freud said concerning man and death. In his work, "Thoughts for the Times on War and Death", Freud develops the main idea of "the impossible belief in one's own death within the unconscious mind". He tells us, "We cannot, indeed, imagine our own death; whenever we try to do so we find that we survive ourselves as spectators." That is to say that the subject does not believe in his own death, or what amounts to the same in the unconscious is that each person is convinced of his own immortality. I know I am mortal, but I want to be immortal clearly summarizes Freud's reflections on the ambivalence that we talked about earlier. When referring to his own death, the subject both knows and doesn't know. In other words, it is completely plausible to think about one's own death but this very thought is inadmissible in its totality: it is the complete inclusion, the full embodiment that is truly impossible within this theory.

Thus, there exists a fissure at the centre of a person's psyche: one part accepts death, while the other refuses to submit (this part we have defined elsewhere [14] as the external part). This interior division that resides in each person is the direct reflection of the conflict between the conscious part and the unconscious part of a human being. When it is the rational and reasonable part of the mind that is heard, the subject can easily speak of his impending death, prepare for his disappearance, prepare loved ones for his passing... When the psychological part of the mind which refuses to die comes to centre stage (ahead of thought and speech), then the individual's words become contradictory and potentially irrational... The subject loses his reasoning and pretends that there is no threat... However, the subject still says something that is meaningful.

This model emphasizes the presence of a subject that vacillates between two different sides: one which represents reality and the other, the imaginary. We believe that this vacillation can play a crucial role for the subject up until the end of his life.

Psychologically speaking, there are two mental postures that remain side by side without influencing one another: one "takes reality into account (when) the other denies the reality in question and puts in its place the production of desire" [15], thus a creation of fantasy. In other words, one can see within himself a "simultaneous progression of two lines of contradictory thinking"[6]. We believe that, these divergent thoughts (and by extension the contradictory speech) are by no means problematic, but are very useful for the psychological well-being of a person who is dying.

As a result, and contrary to the field of pain - it is this great divergence that points us toward both fields of practice regarding the concept of fear avoidance - this process of avoidance does not require deconstruction. On the contrary, it suffices just to support the subject in reinforcing this mechanism. More specifically, it is a matter of supporting the 
defence mechanisms that are in place within the subject in order to help him stay connected to the life instinct. As we shall see, any other position risks creating damaging anticipatory grief for the remainder of the time a person has to live.

For Edgar Morin, there are three anthropological assumptions to be made about man: the realistic awareness of death, the traumatic awareness and a look towards the afterlife. This philosopher thinks of his model as a series of simultaneous events that are foundational to individuality. $\mathrm{He}$ further explains that these ideas do not monopolise the daily attention of the human. Death, he says, "is often absent in the field of consciousness, which, by adhering to the present, inhibits what is not present, and in this way man is clearly an animal, that is to say endowed with life. In this perspective, the participation in life simply lived in itself implies a blindness to death [16]" This primary fear of death, thus is coupled with avoidance mechanisms in daily life, which overshadowing it or replace it with beliefs that life continues after death.

The ideas of Morin parallel those of Pascal in which he ascertains that the worries of the day have one objective which is to divert our thoughts away from death: "few people see that our daily activities are a defence mechanism that help us forget the drama of our inevitable end." "In order to find happiness, mankind, not being able to be cured from death, misery and ignorance, decided there was no reason to think about it. [17]"

\section{Clinical Charts}

Three clinical charts illustrate the proposal paradigmatically: the announcement of serious illness, the psychological progress during the illness and eventually the final phase of life, which could include palliative delirium.

\subsection{Fear Avoidance at the Moment of Diagnosis}

"Words can do unspeakable good or cause terrible injury" [18], said Freud. When death is named (or evoked) through the words of the physician, we would say that it strikes directly at psychological impossibility. The infliction of this stress, in turn creates the conditions for trauma. In effect, when a doctor makes a diagnosis of a life-threatening illness, he utters words that exceed the subject's capacity for mental elaboration: the subject cannot incorporate or mentalize the words and is forced to go where he doesn't want to go/cannot go.

Consciously summoned to comprehend death that is looming nearby, the subject becomes paralyzed and stops projecting himself into the future. This first confrontation exposes the subject to his condition of mortality, a condition that he knows well, but sets aside as if it weren't for him, personally... This subjective reaction is almost automatic: something comes to a halt. Temporality is thus suspended in an eternal present. It is the price to pay for medical truth that brings great distress to the subject: the mental anguish that could be defined as a natural reaction to the absence of uncertainty..., the lack of uncertainty facing an imminent death. In that respect, we are critical [19] concerning the contemporary idea that it would be a good idea to give a patient a prognosis, more specifically a prognosis that includes the chances of survival.

However, at that time, the time of the diagnosis, the phase is quite short. In effect, very quickly the physician's words mobilize treatments, indicates the chances of recovery (including statistics), proves therapeutic options..., the words rekindle hope...There is something that breaks open through this medical interchange between patient and doctor, the possibility for the subject to be revived or at least to close the crack that has opened from the negative echoes of the initial diagnosis.

In other words, when a person falls into serious illness, the natural psychological balance, which consists of the mind pretending that death does not exist, sways back and forth. Something gapes open that would never leave a trace in the psyche of the individual: a trace of the meeting with the reality of death. Through the diagnosis, as we have stated before, "the words of the doctor make our fatal outcome possible, believable, imaginable, almost real. Even if what is said is done without cruelty, these words attack the ghost of immortality, a ghost with which the subject plays a game of dupes which helps him endure the inevitable end" [20].

Clinging to the physician's words that he interprets initially as optimistic, the subject regains all or part of his natural psychological balance. This idea prompted Pascal to say, "men are held back from thinking about their tragic existence" [17] or Spinoza to state that "A free man thinks of nothing less than death" [21]...

From that point on, "the patient knows perfectly what the official etiopathogenesis of his illness is (and I add the threat of real death that goes with it), but he feeds, in secret, another (partially) contradictory or complementary theory" [22]..., because of the physician's words that have been reoriented toward life, we could say.

\subsection{Fear Avoidance During Illness: The Psychological Process and Bereavement}

Fear avoidance is a natural and spontaneous human defence mechanism when one is faced with the impossibility of death. This concept becomes increasingly important the closer one draws toward death: we will now demonstrate this idea through our model comparing and contrasting it to E. Kübler-Ross' model and her well-known stages of grief.

To be clear, it is not Kübler-Ross' model in itself that poses a problem, but the way in which it was created and particularly the way that it has been used and implemented; it has sometimes been applied in a direct and overly-simplified fashion in the contemporary world of caregiving.

The model of Kübler-Ross suggests that there is a psychological process, with a clear and linear view, which goes from denial to acceptance passing through the stages of anger, bargaining and depression. This theory comes from her analysis of interviews with 200 patients that were diagnosed with a serious illness and given a poor prognosis 
[13], as she followed them longitudinally from the moment of diagnosis until death.

The findings are very informative in the sense that they allow the subject to identify himself within a psychological scheme. The subject is in denial (saying, "no, not me, it can't be true!"); or anger ("why me? I don't deserve this!" At this stage, we can see the feelings of rage and anger mixed together, feelings that are often directed toward anything... or anyone); or the subject is in bargaining, (meaning that the subject is bargaining with reality..., as he tries to postpone death, which he sees well now); the subject may be in the phase of depression (a phase which, for the author, is akin to a massive and global withdrawal, a kind of time/space collapse that coincides with the recognition of the fatal event); or the subject is in the phase of acceptance (this last phase consist of a sense of resignation where the subject is now more peaceful, peaceful because he isn't fighting anymore against reality, even as it is hard, the subject is accepting).

It is precisely at the time of its clinical application that this theory raises questions. What people often retain of the theory, is the idea that we need to help this patient progress through these phases with the goal of reaching the final stage of acceptance. It means allowing the patient to work with death as it emerges, to help him think about it, talk about it, tame it...This stage of acceptance clearly represents the ideal stage in which to die: when the subject reaches the final stage, that is to say when he accepts reality as it is, he is more peaceful, more calm..., it is time, now, for him to go, to let go..., to die. This theory offers the patient the opportunity to work through grief for himself..., a sort of "mourning of the self before his death". However, mourning before dying amounts to dying subjectively before dying in reality. Any mourning of oneself before one's own death is not only impossible (impossible in its completion, as we saw earlier) but is most often traumatic. What this does is that it adds an additional trauma to what the subject already is struggling to bear!

Considering what is pointed out above, knowing that fear avoidances is a natural and spontaneous human defence mechanism when one is faced with death, the use of KüblerRoss's model represents a problem. By forcing the subject face to face with his own death - something that he does not wish for - the therapist or palliative caregiver creates a psychological trauma which adds to an already difficult situation. Clearly, Kübler-Ross' model puts pressure on the patient's mental health, drawing him toward the most concrete, harsh, cold and realistic medical reality possible. It is precisely in this place even more so where the subject will, spontaneously, seek an escape route that will transport him to an imaginary place, into a Pascalien distraction..., to the side of fear avoidance. In other words, where the model of Kübler-Ross reinforces the feedback loop fear of death/distress -- non-confrontation regarding death - fear of death/distress..., The following approach seems better: fear of death/distress - non-confrontation regarding death life/death instinct ambivalence. That is to say, it is important to let the subject, as much as possible, find this sort of natural avoidance of death... It allows the patient to defend himself psychologically in the most natural way that he knows how, especially because all of this occurs without the knowledge of the patient, without inciting his will to do so. However, the position of the accompanying and caregiving third parties is important, their expectations, what they say - this is quite decisive.

"La mort ne s'affronte pas... !",[12]. When we wrote this in 2011, we emphasized the importance of supporting the psychological defence mechanisms of patients instead of wanting to confront them with their finitude. Today we would say that it is the capacity to continue with ordinary life that diminishes the fear of death. And this capacity can be hindered or encouraged by their caregivers, that is to say by the way they are present with the patient, in their relationship and with their particular use of speech. In effect, the approach advocated for here involves a specific clinical protocol, one in which we leave our own beliefs aside, and place trust in the Other. It consists of, firstly and above all, being completely supportive to the subject in his verbal expression, meaning giving him freedom from the medical reality which envelops him. It means that everything will be put into place in order not to hinder the psychological dynamic that creates distraction where the subject tries "not speak about his death", or to "think about something else", or to "talk about something else". To be on the side of life left to live, not on the side of death, the subject sheds this fascination of imminent death... as explained elsewhere: "The work to be done consists of turning the drive to know more and more about the medical-biological reality towards a form of ignorance more in line with the way the psychological mind functions in relation to death. Additionally, sometimes clinical encounters can produce a desired stimulus in the patient by putting thought back into motion, encouraging the liberation of the subject from a premature psychological death"[3]. Ethically speaking, we propose a model where the caregiver should try to stay the course with the subject so that he may eventually "die forgetting that death exists [23]".

\subsection{Fear Avoidance in the Final/Distress Phase: Delirium}

It is a fact that cannot be denied; at the end of life, confrontation with death becomes more acute, more palpable and more real. As the subject himself ignores the signs, the attitudes, words and gestures of those around him will call to mind this reality. It is as if the work of death, already in place, already there..., now becomes so powerful that almost nothing and no one can aid the patient in their final attempts of avoidance... In fact, in clinical reality, it is as if there were a limit, a limit that was "accepted" by those loved ones who remained alongside the patient during the illness, but this limit no longer exists at the present moment. The game of "dupe" that the patient entertained with himself and with others during the period of the illness in the form of evasion, false beliefs, and sweet illusions - is now virtually impossible to sustain. Reason and what is reasonable both begin to saturate the patient's thoughts and take centre stage!

Almost nothing and no one can now hold the subject up in 
his final attempts of evasion: it is in the almost that we would like to specify, our hypothesis which is that fear avoidancethe fact of $\neg$ psychologically defending oneself against death - is never more important than at the very end of life. The closer the patient draws to death, the more we observe what international literature today calls the mechanism of palliative delirium[24]. In this framework, delirium - and more generally, disoriented speech - would be the only psychological reaction when faced with the acute trauma of the arrival of death.

The high frequency of cases of delirium at the end of life directly support our assertion. These particular mental creations [25] allow the patient to protect himself against the unbearable. This natural and spontaneous psychological progression here has a significant purpose, which is to ease and soften the passing into death.

However, for this to occur, it is again necessary not to inhibit the process itself. This is not always easy, particularly when one has close ties to the patient.

A 55-years-old patient with Gastro-Intestinal cancer invites small insects, particularly ants to visit her regularly. She maintains a strange and infantile conversation with them. And it seems that all of this does not bother her. She does not verbalize it directly, of course, but the way that she expresses herself and her attitudes indicate a kind of comfort in these pleasant hallucinations.

In this manner, the confusion seen at the end of life can be thought of as the last form of fear avoidance. Like all denial, it should be welcomed and not castaway [26]. This idea refers to all confusion/hallucination that we have described as pleasant. We cannot approach confusion that puts the patient or his loved ones in danger in the same way.

What it was pointed out throughout this article how falling into a state of denial is traumatic and is not something desired by subject himself. However, here a decrease in confusion, would bring the patient back into confrontation his own death. Thus, it is through delirium, that the psychological mind becomes victorious in its quest to flee. This brings up a delicate question: until what point should the end of life be mediated through medical care? [27]

Delirium can be akin to an interior division. When nearing death, this necessary fissure that we have referred to earlier and which aids the subject in holding on, literally bursts open under the pressure of the concrete reality of death. In other words, the irrational part, the fantastical takes centre stage, while the thread of reason is lost.

And what if, paradoxically, this swing of the pendulum points to an inner force at work?

Irrational speech is thus comprehensible: the subject has de-railed, he has left the track... But, it is precisely this derailment that is useful for the patient..., just as useful for the patient as it is disturbing and frightening for the caregivers and loved ones remaining at his side.

The part containing reason dies, while the other part (the soul?) continues to live, within the imagination, in another world: the world of the irrational and of beliefs. Perhaps some subjects are only able to die by realising this interior division? If that were the case, this would call to question the terms and conditions of responding to the state of delirium...Perhaps certain subjects would find that confusion is the final way to escape from a reality which is too harsh [3].

\section{Conclusion}

This article give to the mechanism of fear avoidance all the place it deserves within the caregiver consciousness, in taking it outside the original field which brought it to light. The mechanism of fear avoidance, whether from the moment of diagnosis of serious illness, during the psychological process that accompanies the illness, or in the final moment of death, allows the patient to die, psychologically speaking, more comfortably. For the subject, this fear avoidance mechanism represents a real life-saving defence, psychologically speaking. Most certainly, because of fear avoidance the subject can defend himself against the threat of death which, when conveyed through the medical diagnosis, is always overwhelming, frightening and paralyzing. Due to this process, the patient reacts and does not allow the death instinct to have the last word in life: "not even to crack the window, just a little bit", as we wrote subsequently.

Clinically, the difficulty lies in letting the process be entirely guided by this mechanism, and thus trusting the human and his psychological creations. On one hand, it is important because fear avoidance is a psychological process that is natural and occurs spontaneously (as we have stated on numerous occasions throughout the text), a mechanism that is almost a reflex which, like all mechanisms of the body make sense and serve a function that should be respected. On the other hand, because any stance that diverges, meaning one that would push the other towards the acceptance of his death, risks adding a supplementary trauma to the subject who is already in full battle against the initial trauma of the disease.

\section{References}

[1] Vlaeyen JWS, Crombez G, Linton SJ. (2016) The fearavoidance model of pain. Pain, 157:1588-1589.

[2] Wertli MM, Rasmussen-Barr E, Held U, Weiser S, Bachmann LM, Brunner F. Fear-a]voidance beliefs - a moderator of treatment efficacy in patients with low back pain: a systematic review Spine J 2014;14: 2358-2678.

[3] Alric J. End of life \& Psychoanalysis Death threat and return to desire (Only in French) Fin de vie \& Psychanalyse Menace de disparition et relance désirante Montpellier Sauramps Médical 2016.

[4] Amar S. Palliative care support Psychoanalytic Approach (Only in French) Paris Dunod 2012.

[5] Doucet C. Palliative care clinical and death metapsychological problem (Only in French. L'Evolution psychiatrique 2005; 70 605-612. 
[6] De M'Uzan M. Demise work Of the art in the death (Only in French) Paris: Gallimard, 1976; 182-199.

[7] Alric J. \& all. Stay alive with disease Psychoanalytic approach in oncology and palliative care (Only in French) Clinique psychanalytique en cancérologie et en soins palliatifs Erès 2015.

[8] Rolving N1, Nielsen CV, Christensen FB, Holm R, Bünger CE, Oestergaard LG. Does a preoperative cognitivebehavioral intervention affect disability, pain behavior, pain, and return to work the first year after lumbar spinal fusion surgery? Spine 2015; 40: 593-600.

[9] Andersen TE, Karstoft KI, Brink O, Elklit A. Paincatastrophizing and fear-avoidance beliefs as mediators between post-traumatic stress symptoms and pain following whiplash injury A prospective cohort study Eur J Pain 2016; 20: $1241-52$.

[10] Jay K, Brandt M, Jakobsen MD, Sundstrup E, Berthelsen KG, Schraefel M, Sjøgaard G, Andersen LL. Ten weeks of physical-cognitive-mindfulness training reduces fearavoidance beliefs about work-related activity: Randomized controlled trial. Medicine (Baltimore) 2016 Aug; 95 (34): e3945. Doi: 10.1097/MD.0000000000003945.

[11] Fritz JM, Magel JS, McFadden M, Asche C, Thackeray A, Meier W, Brennan G. Early Physical Therapy vs Usual Care in Patients with Recent-Onset Low Back Pain: A Randomized Clinical Trial. JAMA. 2015; 314: 1459-1467.

[12] Alric J. The appeal to the eternity in the psychic life The death is not in confrontation (Only in French) Alric J \& Bénézech JP. La mort ne s'affronte pas...! Montpellier Sauramps Médical 2011 59-69.

[13] Kübler-Ross E. On Death and Dying. Genève Labor et Fides 1969.

[14] Alric J. I am going to live just like that The psychic sufferings of the sick of the cancer: How to recognize them, how treat them? (Only in French) Dudoit E \& Ben Soussan P. Les souffrances psychiques des malades du cancer. Comment les reconnaître, comment les traiter? Paris: Springer-Verlag 2009: 35-39.
[15] Laplanche J. \& Pontalis JP. The Language of Psychoanalysis Puf 10ème édition 1990: 67.

[16] Morin E. Human and the death. Edition Seuil 1970 (première publication en 1951).

[17] Pascal B. Pensées. Edition Brunschvicg (réedition 1965).

[18] Freud S. 1926. Psychanalyse et Médecine Ma vie et la psychanalyse Paris Gallimard 1972: 95-184.

[19] Bénézech JP. Is prognosis ethical? Médecine Palliative 2008; 7: $140-148$.

[20] Alric J. Thaveau L. \& all. Of already there of the death in the disappearance of the finiteness Psychoanalytic approch in oncology (Only in French) Etudes sur la mort, Thanathologie Les fins de vie Paris: Esprit de temps 2010/2: 30.

[21] Spinoza. Ethics. Trad. A. Guérinot, L'éthique de Spinoza, Paris: Ivrea, 1993.

[22] Pédinielli J-L. patient's personnal theories. Pratiques psychologiques 4 1999: 53-62.

[23] Mannoni M. Named and unnameable. Paris Denoël 1991.

[24] Hjermstad MJ, Loge JH, Kaasa S. Methods for assessment of cognitive failure and delirium in palliative care patients: implications for practice and research. Palliative Medicine 2004; 18: 494-506.

[25] Wong CL, Holroyd-Leduc J, Simel DL, Straus SE. Does this patient have delirium? Value of bedside instruments. JAMA 2010; 18: 779-786.

[26] Campbell N, Boustani MA, Ayub A. and All. Pharmacological Management of delirium in hospitalized adults-a systematic evidence review. J Gen Intern Med 2009; 24: 848-853.

[27] Bénézech JP. What are the limits to the medicalization of the end-of-life period? Éthique et santé 2012; 9: 55-59. 